\title{
تداعيات جائحة كورونا (كوفيد-19) على أداء وكالات السياحة والأسفار
}

\section{سماعيل حسيبة}

طالبة دكتوراه- مخبر تنمية تنافسية المؤسسات الصغيرة والمتوسطة الجزائرية في مجال صناعة البدائل المحلية، جامعة حسيبة بن بوعلي بالشلف- الجزائر h.smail@univ-chlef.dz

\section{بن نافلة قدور}

أستاذ- مخبر تنمية تنافسية المؤسسات الصغيرة والمتوسطة الجزائرية في مجال صناعة البدائل المحلية، جامعة حسيبة بن بوعلي بالشلف- الجزائر k.bennafla@univ-chlef.dz 
International Journal of Hospitality and Tourism Studies

(IJHTS)

Journal Homepage: https://www.refaad.com/views/IJHTS/home.aspx

ISSN 2709-0892 (Online) ISSN 2709-0884 (Print)

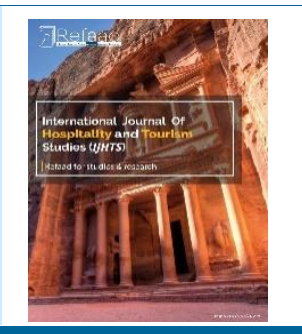

\section{تداعيات جائحة كورونا (كوفيد-19) على أداء وكالات السياحة والأسفار}

\section{سماعيل حسيبة}

طالبة دكتوراه- مخبر تنمية تنافسية المؤسسات الصغيرة والمتوسطة الجزائرية في مجال صناعة البدائل المحلية، جامعة حسيبة بن بوعلي بالشلفالجزائر

h.smail@univ-chlef.dz

\section{بن نافلة قدور}

أستاذ- مخبر تنمية تنافسية المؤسسات الصغيرة والمتوسطة الجزائرية في مجال صناعة البدائل المحلية، جامعة حسيبة بن بوعلي بالشلف- الجزائر k.bennafla@univ-chlef.dz

DOI: https://doi.org/10.31559/IJHTS2021.2.1.2 2021/6/22 2021/4/5 مراجعة البحث: 2021/5/19 قبول البحث

تهلدف هذه الدراسة إلى إبراز الانعكاسات والآثار التي خلفتها جائحة كورونا (كوفيد-19) على أداء وكالات السياحة والأسفار عالمياً ووطنياً

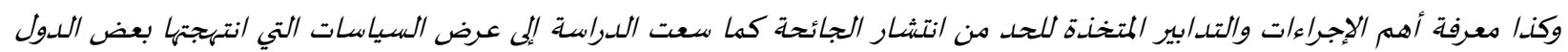

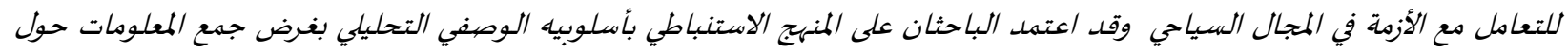

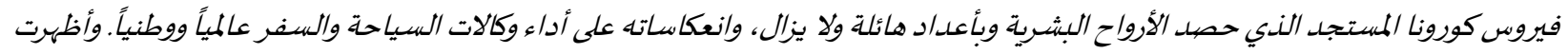

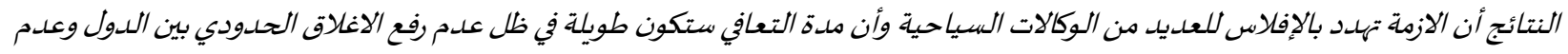

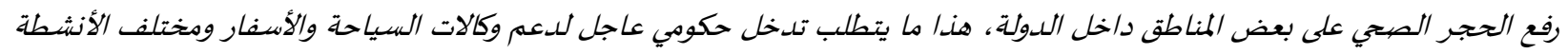

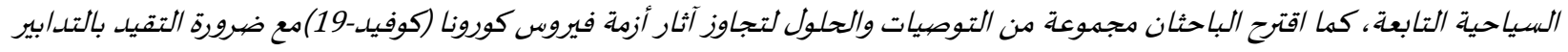

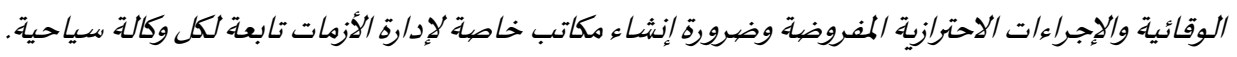
الكلمات المفتاحية: فيروس كورونا؛ كوفيد-19؛ وكالات السياحة والأسفار؛ تداعيات الجائحة.

تعتبر السياحة من أهم الصناعات العالمية التي تدر عائدات هائلة على اقتصاديات الدول، إذ نجد عديد الدول من مختلف القارات يعد القطاع

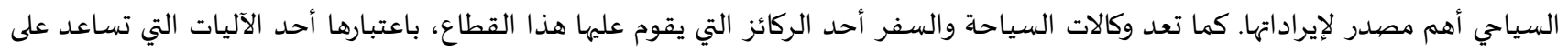

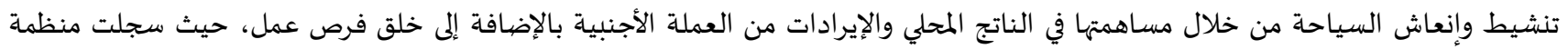

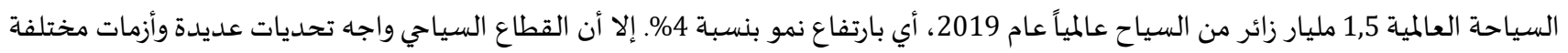

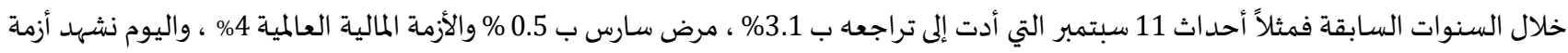

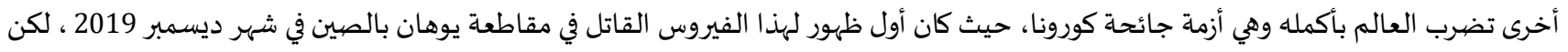

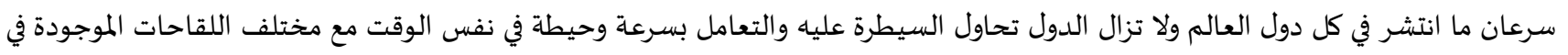
السوق، فقد تسبب في إصابة أكثر من 17 مليون شخص في العالم وفق إحصاء لوكالة رويترز في 31 جويلية 2020 ، ولكن مع إستمرار الوضع وتوالي

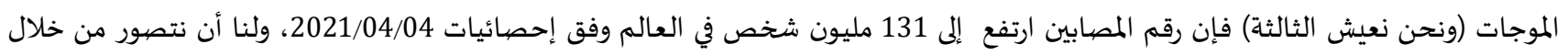

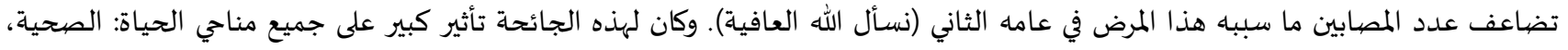


الاقتصادية، السياسـة الاجتماعية والرياضية....الخ، والتي ستكون لها أيضاً تداعيات سلبية على القطاع السياحي وعلى الأخص على وكالات السياحة والسفر في سياق الإجراءات المشددة التي اتخذتها دول العالم للحد من انتشـار العدوى والسيطرة على الأعداد المتزايدة من الإصابات من خلال غلق

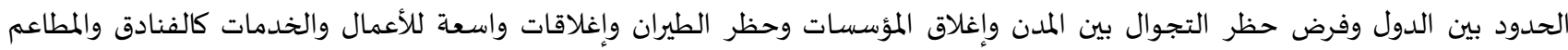

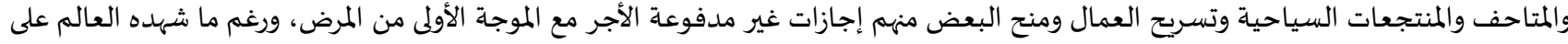

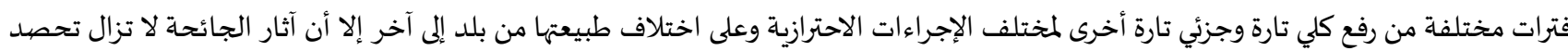

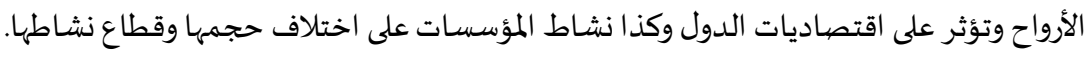

1.1

إن الآثار والمخلفات السلبية التي سببتها جائحة كورونا منذ بدايتها (ديسمبر 2019) لم يسلم منها ولا قطاع ولم تستطع تجاوزها حتى الدول التي

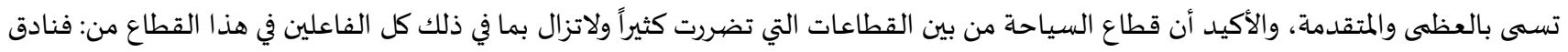
وشركات طيران ومطاعم ومنتجعات ووكالات السياحة والسفر، مما سبق عرضيه يمكننا طرح المشكلة التالية:

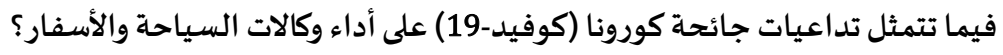

وتحت هذه المشكلة الرئيسة نضيع المشكلات الفرعية التالية:

كيف يمكن توصيف فيروس كورونا (كوفيد-19)، وما هي الإجراءات المتخذة للحد من انتشاره؟

ماهي التداعيات الناجمة عن فيروس كورونا (كوفيد-19) على أداء وكالات السياحة والسفر عالمياً ووطنياً؟ ما هي مختلف الاقتراحات والتوصيات لفائدة وكالات السياحة والأسفار لتخطي الأزمة؟

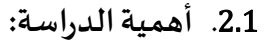

تكتسب الدراسة أهميتها من مجموعة من النقاط، يمكن إيجازها فيما يلي:

الدور الفعال الذي يلعبه قطاع السياحة في اقتصاديات الدول وكذا مساهمة وكالات السياحة والسفر في دفع عجلة هذا القطاع. تأثير جائحة كورونا (كوفيد-19) على كل القطاعات لاسيما قطاع السياحة.

ضرورة تفكير الحكومات عموماً ووكالات السياحة والسفر بالأخص، في كيفية تجاوز الآثار السلبية الكبيرة التي خلفتها الجائحة على كل الفاعلين في المجال السياحي. ضرورة مراجعة داء وكالات السياحة والأسفار في الجزائر. ضعف مساهمة قطاع السياحة في الجزائر يفرض على وكالات السياحة والأسفار في الجزائر أن تضاعف مجهوداتها لمحاولة تقليص الفجوة الموجودة بين كل من الطلب والعرض السياحيين.

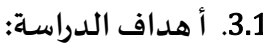
تهدف هذه الدراسة إلى: - ماسه: إظهار الآثار التي خلفتها الجائحة على قطاع السياحة عموماً وعلى أهم الفاعلين في المجال والمتمثل في وكالات السياحة والأسفار. عرض نماذج لدول استطاعت التعامل مع الجائحة بنجاح في مجال السياحة. محاولة تقديم مقترحات قد تساعد وكالات السياحة والسفر على تجاوز الأزمة على المدى القريب والبعيد. المساهمة في تبيان الفرص الضيائعة أمام وكالات السياحة والأسفار في الجزائر لا سيما في السوق الداخلية. التأكيد على اعتبار جائحة كورونا (كوفيد-19) فرصة وليس أزمة أمام وكالات السياحة والأسفار في الجزائر لمراجعة عديد الأمور من هيكلة تنظيمية ومزيج خدمات. 


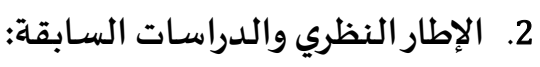

1.2. الإطار النظري

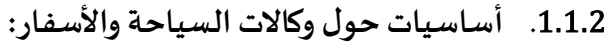

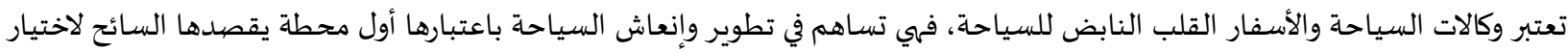

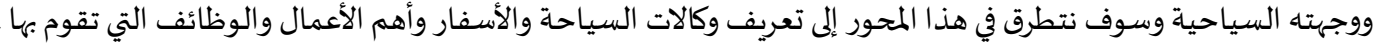

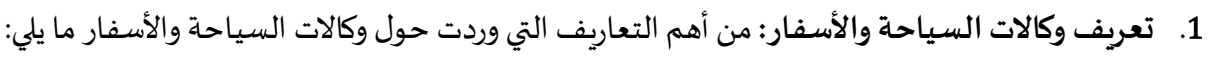

عرفت على أنها:" مؤسسات تجارية تدار من قبل شخص طبيعي أو معنوي، والذي يقترح للعملاء خدمات سياحية تتمثل أساساً في السفر،

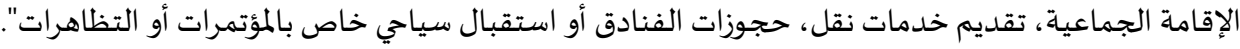

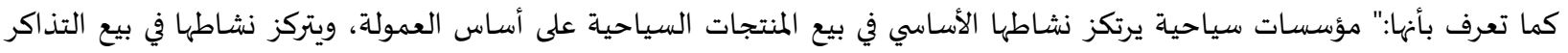

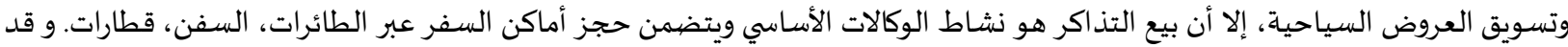

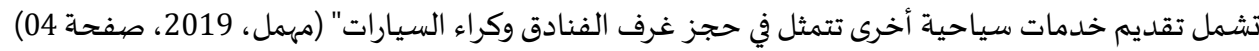

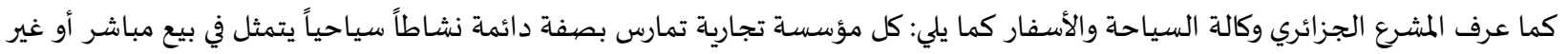

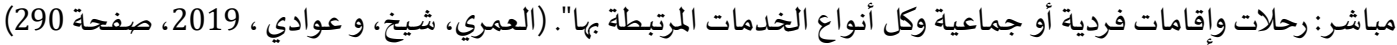

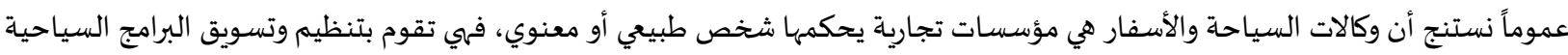

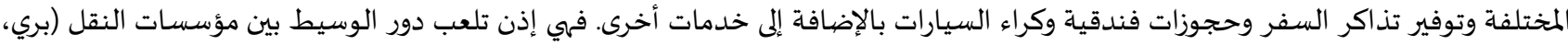

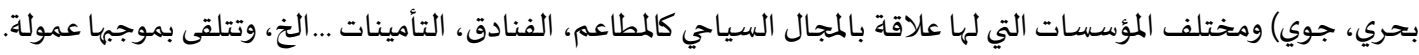
2.

تنظيم وتسويق أسفار ورحلات سياحية وإقامة ووضعها تحت تصرف السات السياح. تنظيم زيارات وجولات برفقة مرشدين داخل المدن والمواقع الأثرية ذات طابع سياحي وثقافي وتاريخ وديني. وضع خدمات المترجمين والمرشدين السياحيين تحت تصرف السياح الأجانب ومساعدتهم خلال فترة الإقامة. الإيواء أو حجز الغرف في المؤسسات الفندقية وتوفير الخدمات المرتبطة بها.

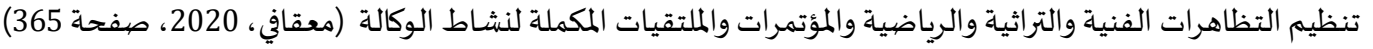
توفير النقل السياحي وبيح كل أنواع تذاكر النقل حسب الشروط والتنظيم المعمول بهما لدى مؤسسات النقل. بيع تذاكر أماكن الحفلات الترفيهية والتظاهرات ذات الطابع الثقافي أو الرياضي أو غير ذلك. استقبال ومساعدة السياح خلال إقامتهم. القيام بإجراءات التأمين من كل المخاطر الناجمة عن نشاطاتهم السياحية.

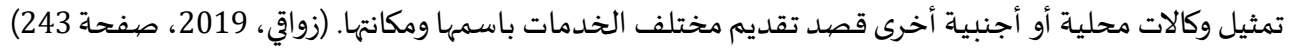
3. واجبات وكالات السياحة والأسفار: وتتمثل في الواجبات العامة وواجبات الوكالات السياحية تجاه السائح (معقافي، 2020 ، صفحة 366 3. الواجبات العامة: تتمثل فيما يلي: ممارسة النشاط مع الاحترام الصارم للأحكام التشريعية والتنظيمية السارية المفعول. احترام أخلاقيات وقواعد المهنة وتكريس الاحترافية. • تطوير السياحة الإلكترونية وإدماج التقنيات الحديثة للتسيير والتسويق للمقصد السياحي والنشر الدوري لمختلف الوسائل الترقوي ذات التراتية الجودة.

احترام البيئة والتراث المحلي والمحافظة على المناطق والمواقع السياحية التي يتم زياتها. الواجبات تجاه السائح: • الإبرام التلقائي لعقد السياحة والأسفار مع كل زبون والسائح المتكفل بها. تلبية احتياجات الزبائن والسياح فيما يخص محتوى وبرنامج الرحلات السياحية حسب الطلب. التكفل بكل الخدمات المتفق عليها واحترام الالتزامات المتعاقد عليها. التأطير الفعلي والفعال للسياح في كل مراحل المنتوج السياحي المتفق عليه 
الامتناع عن الاشهار الكاذب فيما يخص الأسعار أو الخدمات.

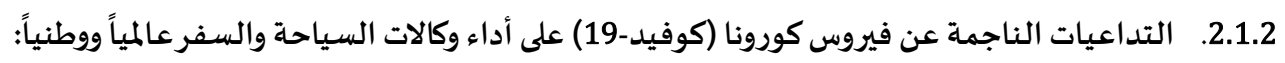
• حقائق عن فيروس كورونا (كوفيد-19) وأهم الإجراءات المتخذة للحد من انتشاره:

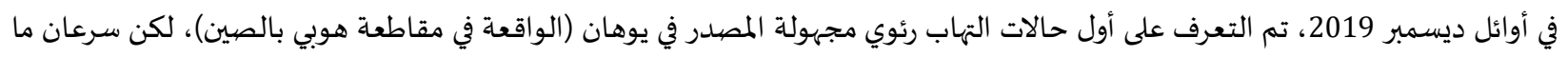

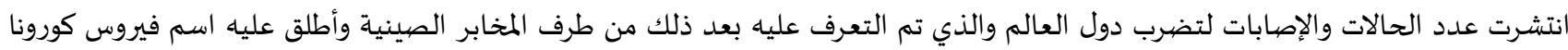

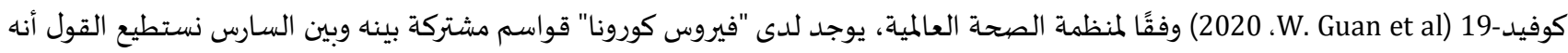
من نفس العائلة وقد ظهر مرض السارس بشكل ملحوظ في الصيين من عام 2002 إلى عام 2004 ، حئ حيث أصاب أكثر من

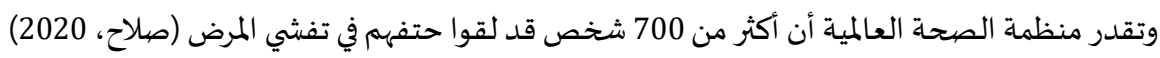

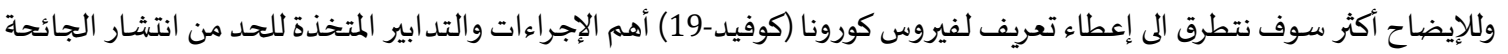

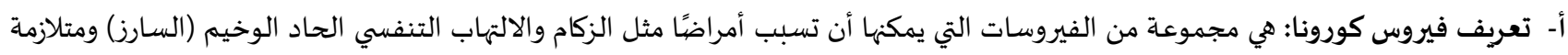

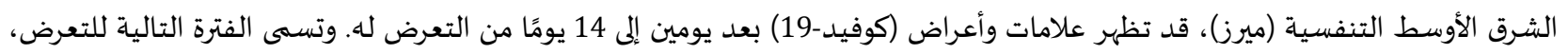



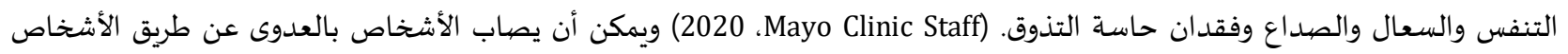

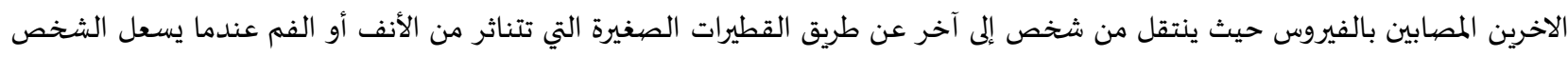

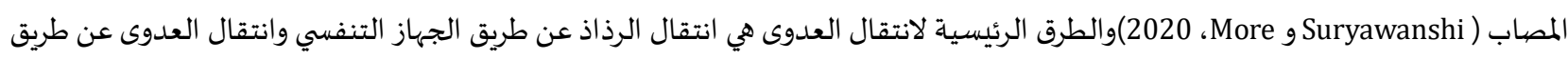

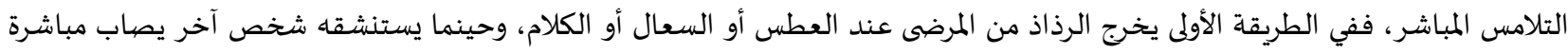

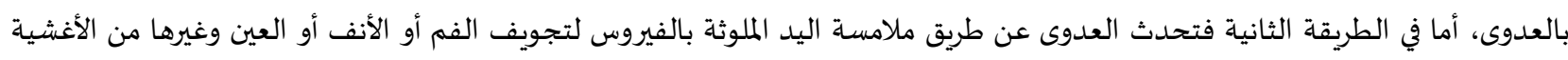

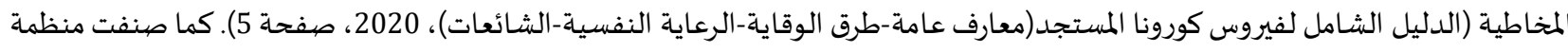

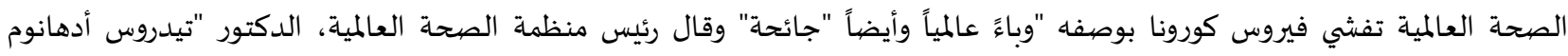

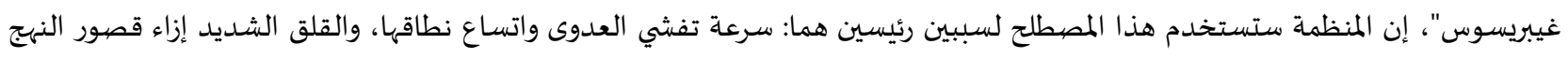

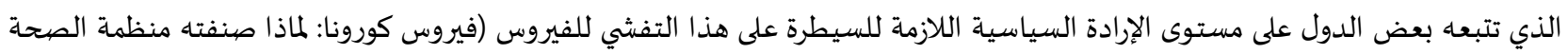

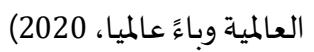

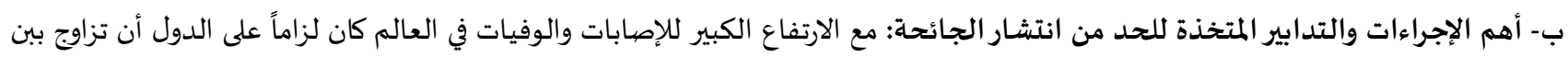

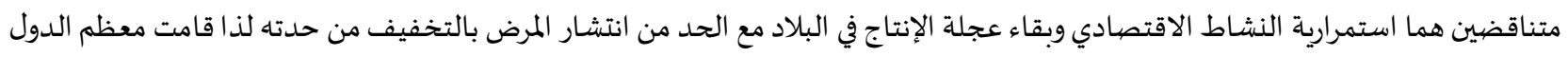

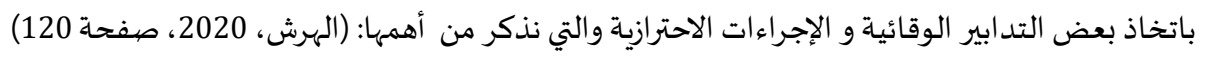

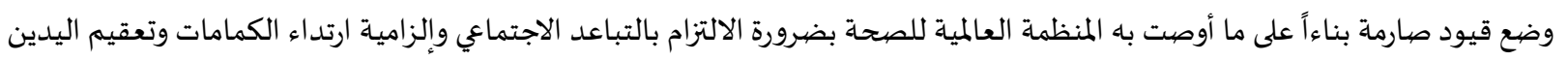
خاصة في الأماكن العامة. غلق جميع الحدود البرية والجوية والبحرية ماعدا نقل البضائع والسلع والمستلزمات الطبية... الخّ.

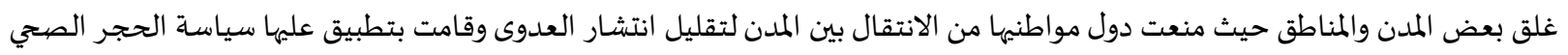

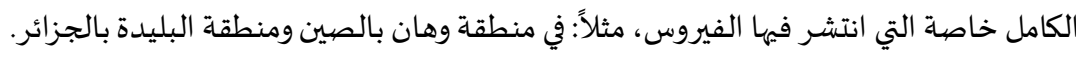

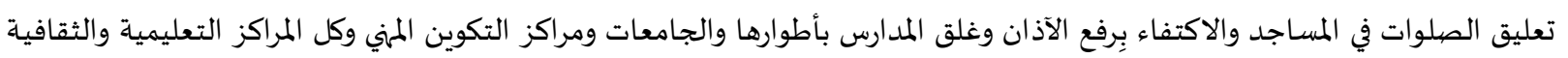
الخاصة والعمومياة.

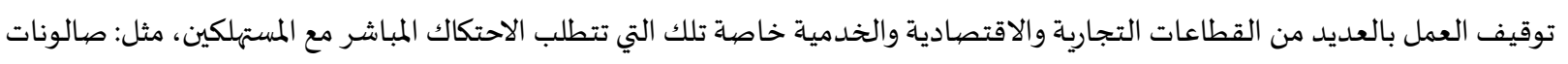

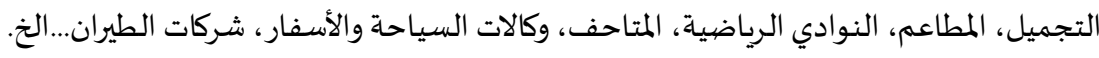

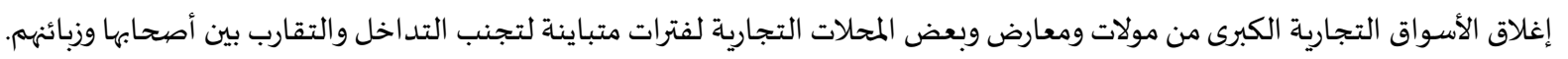

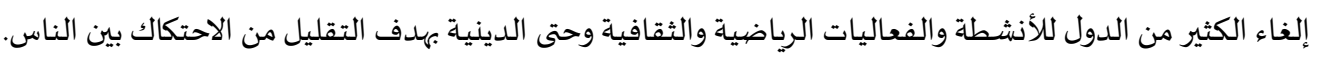

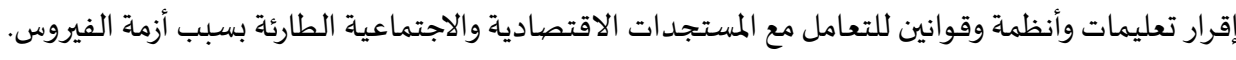

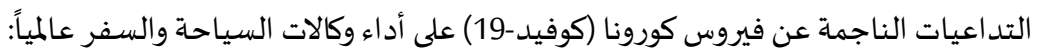

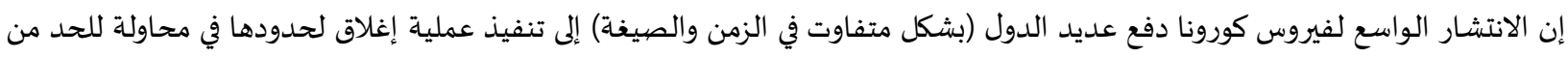






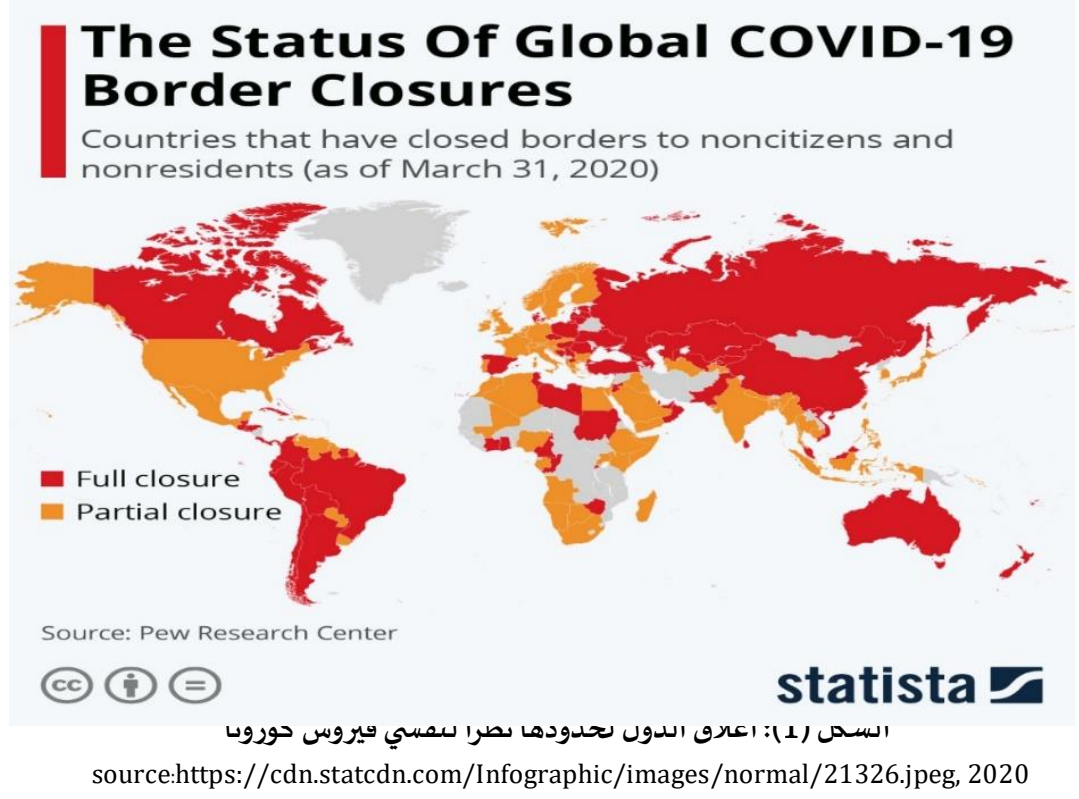

وحسب ما يوضحه الشكل رقم 1 فغالبية الدول لجأت إلى الاغلاق الكلي للحدود، مما تسبب بالضرر لكل القطاعات الإنتاجية والاقتصيادية

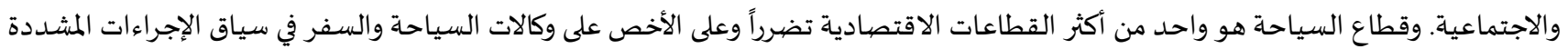
التي اتخذتها دول العالم للحد من انتشار العدوى والسيطرة على الأعداد المتزايدة من الإصابات من خلال فرض حظر التجوال وإغلاق المؤسسات وحظر

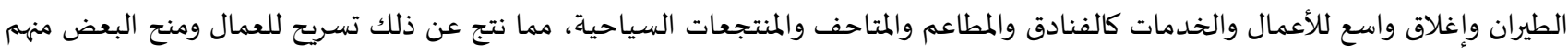

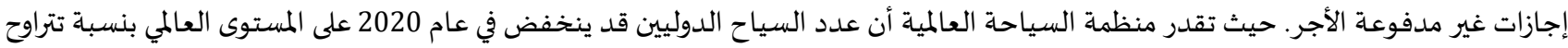

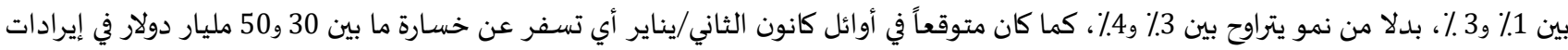

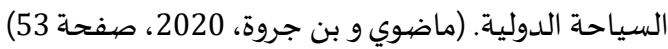

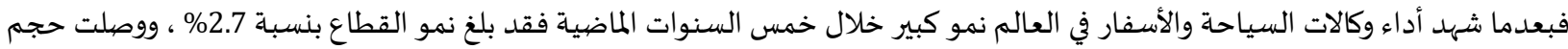

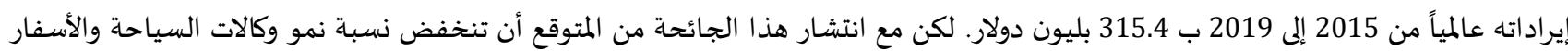
عالميا ب 2.1\% خلال عام 2020 (IBISWorld, 2020) كما أن منظمة الطيران المدني ATA قدرت انخفاض عائدات الركاب بما يقارب 252 مليار دولار أي بنسبة 44\% بام بالمقارنة مع 2019 ، في حين قالت

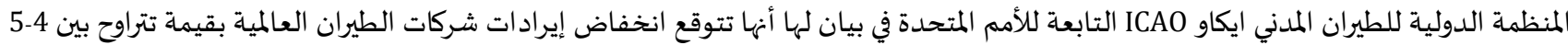

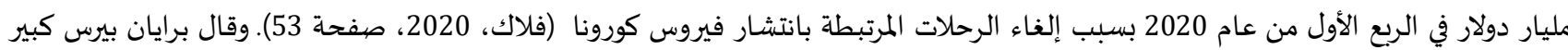

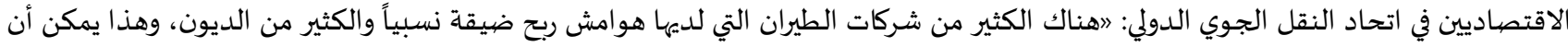

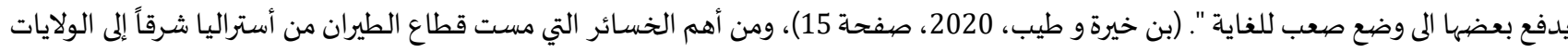

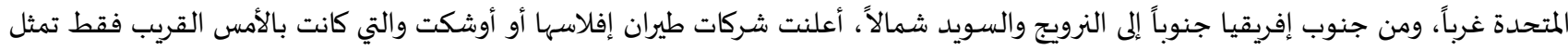

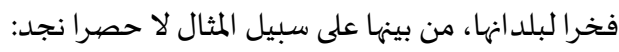

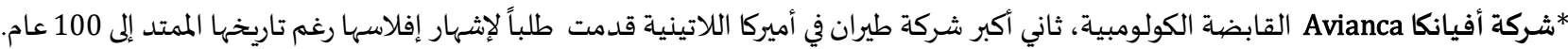

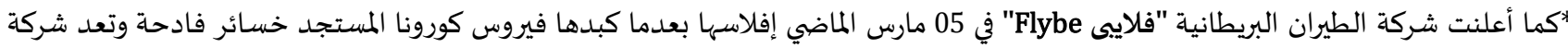

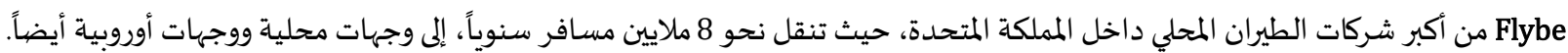

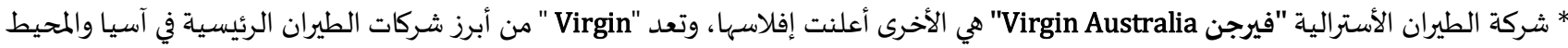

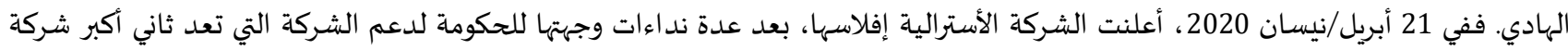

طيران في البلاد... (2020، (Insider) * في جنوب إفريقيا انضمت شركة الطيران الوطنية، South African Airways إلى طابور الشركات التي أعلنت إفلاسها، متأثرة بجائحة كورونا إذ أعلنت الشركة إفلاسها وتسريح موظفيها البالغ عددهم 4700، بعد فشلها في الحصول على مسـاعدات مالية ودعم حكومي. وتعد الشركة هي الأقدم والأكثر

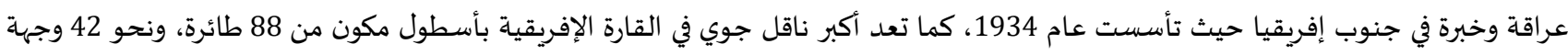
إفريقية وعالميية. (يتي، 2020) 
وحتى تلك التي لم تشهر بعد إفلاسها فقد أنقضتها المساعدات المالية التي ضختها لها حكوماتها، مثلاً:

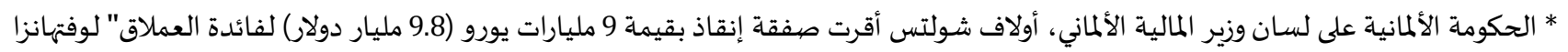

."Lufthans

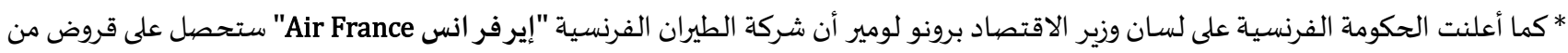

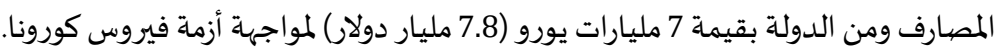



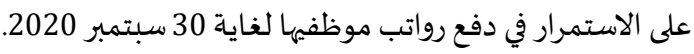

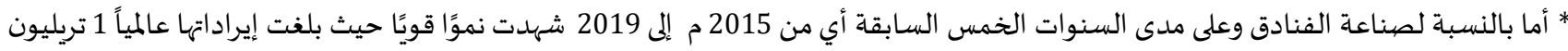

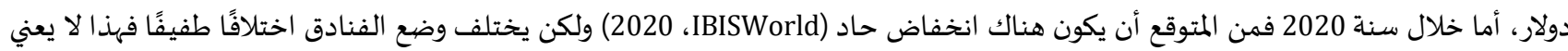

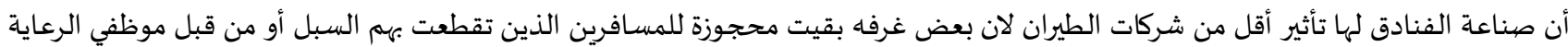

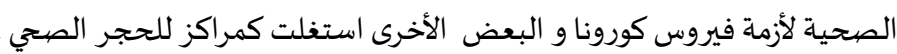

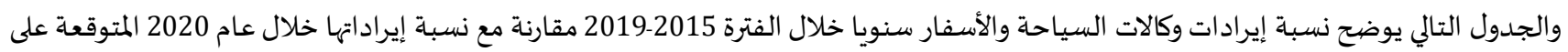

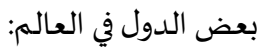

جدول (1): توقعات انخفاض إيرادات وكالات السياحة والأسفار

\begin{tabular}{|c|c|c|}
\hline 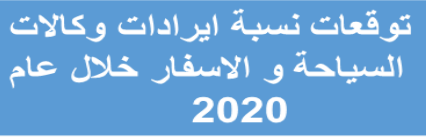 & 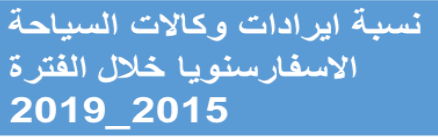 & اسم البلد \\
\hline$\% 17,31$ & $\% 0,8$ & الصين \\
\hline$\% 13,8$ & $\% 1,3$ & الام لايات المتحدة \\
\hline$\% 23,2$ & $\% 4,7$ & ألمـانيا \\
\hline$\% 24,3$ & $\% 2,9$ & أستر اليا \\
\hline$\% 4,1$ & $\% 2,3$ & المملكة المتحدة \\
\hline
\end{tabular}

المصددر: من إعداد الباحثين بالاعتماد على الموقع

-BISWorld. (2020, 05 06). Global Hotels \& Resorts Industry- Market Research Report. Consulté le 08 10, 2020, sur https://www.ibisworld.com/global/market-research-reports/global-hotels-resorts-industry/.



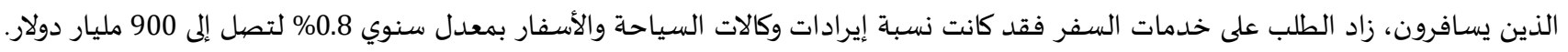

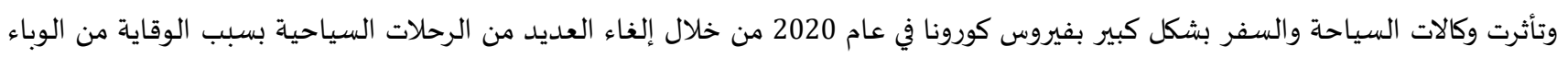

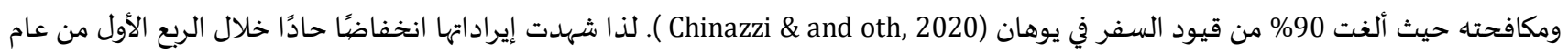

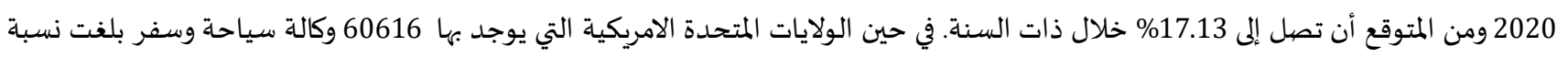

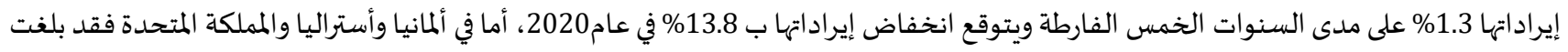

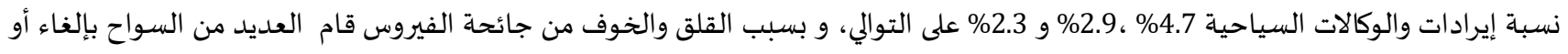

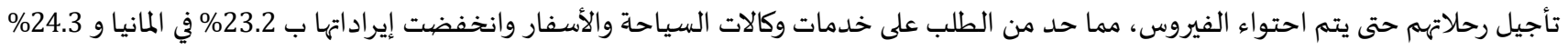

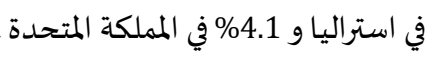

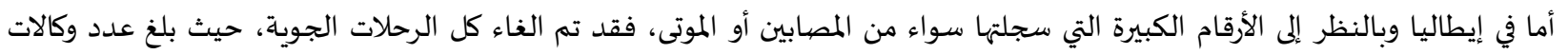

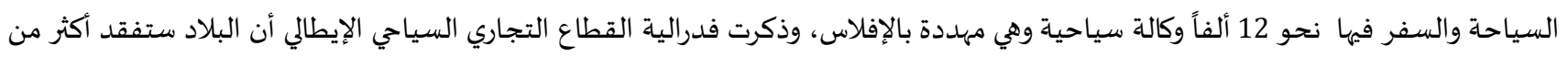

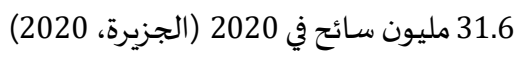

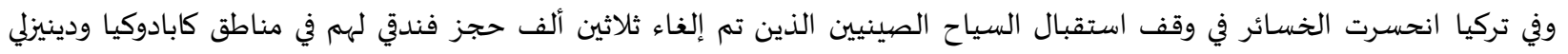

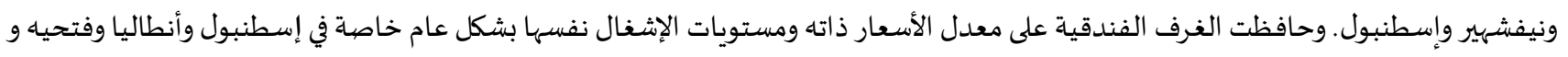

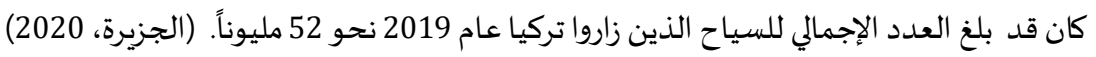

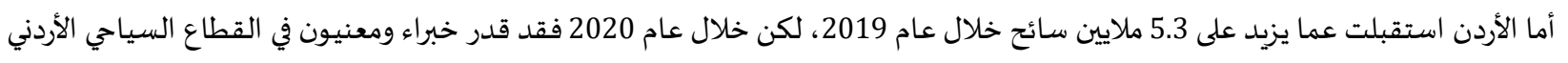

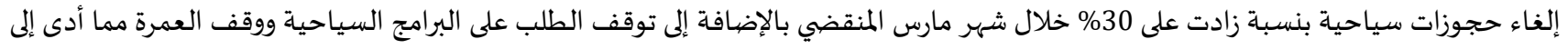


مزيد من الخسائر، خاصة أن نحو سبعة آلاف معتمر حصلوا على تأشيرات للعمرة، وبتكلفة 140 ألف دولار تقربباً كما قد تم إلغاء الفعاليات السياحية بمختلف أنواعها. كما بلغ عدد السياح الوافدين على مصر أكثر من 12 مليون سائح 2019 وكان متوقعاً زيادة الرقم بنسبة 30\% خلائل التهال 2020 ، لكن ومع تفشي الجائحة فقد انخفضت نسبة الحجوزات السياحية بين 70\% إلى 80

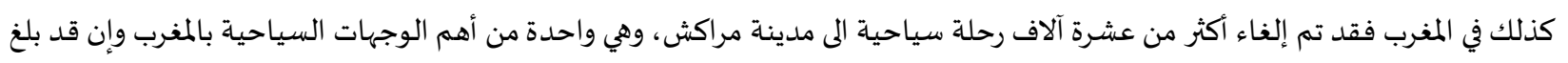

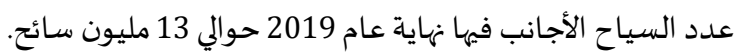

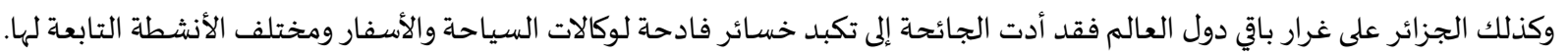

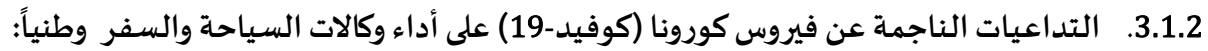

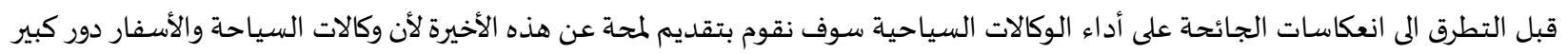

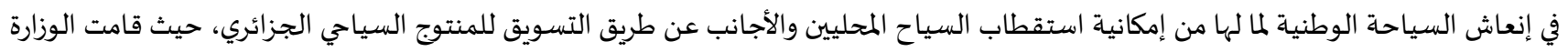

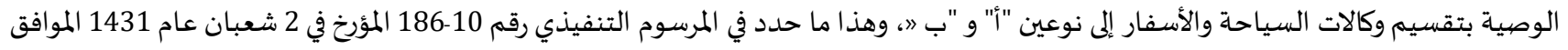
لـ 14 جويلية سنة 2010، والذي يعدل ويتمم المرسوم التنفيذي رقم تنظيم وكالات السياحة والأسفار واستغلالها: وكالات سياحية تنشط بصفة رئيسية في "السياحة المستقطبة أو المستقبلة "، أي يرتكز عملها على استقطاب السياح المحليين والأجانب وتصنف

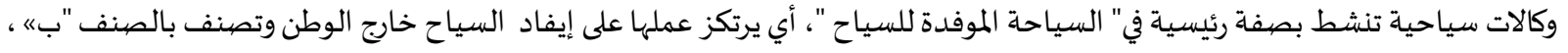

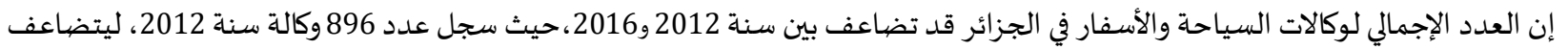

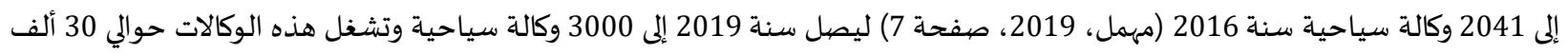
منصب عمل (الاذاعة الجزائرية، 2020).

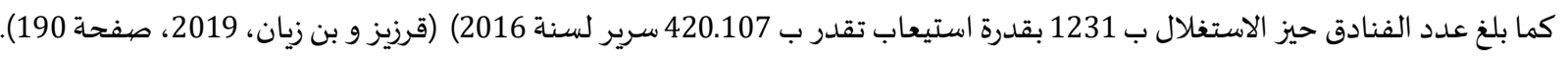

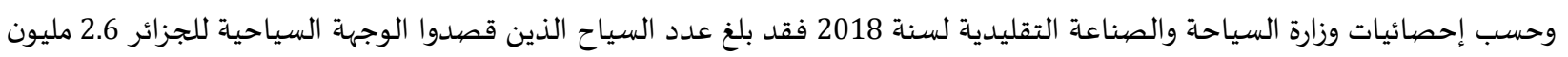

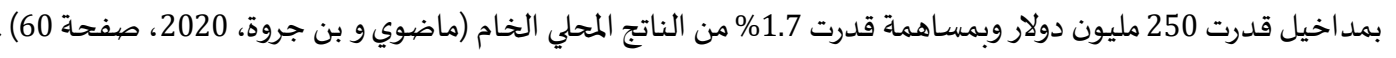

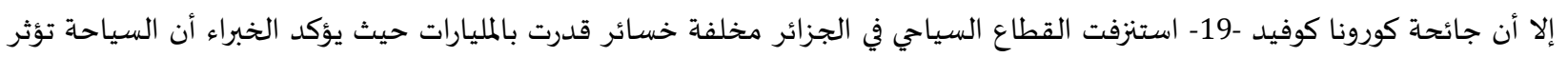

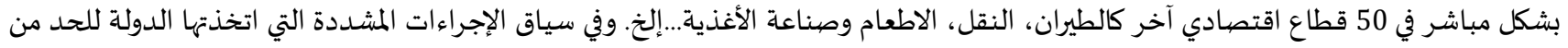

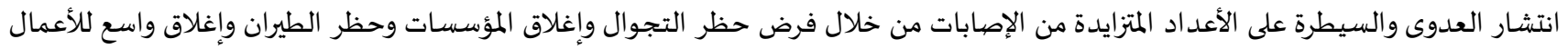

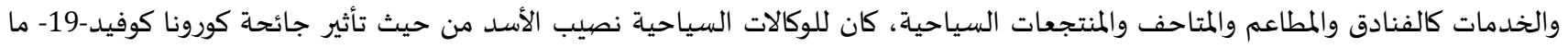

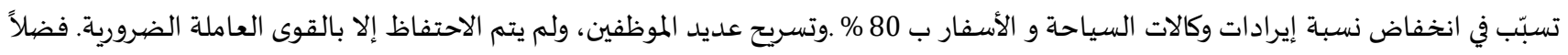

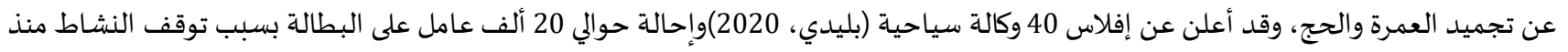

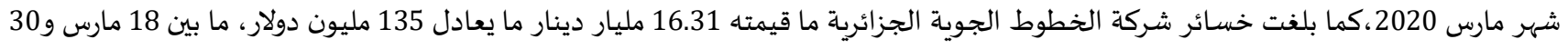

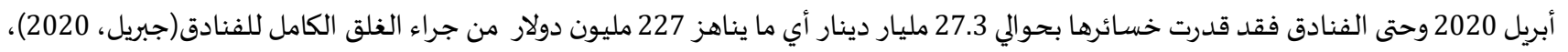

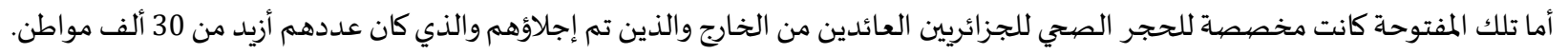

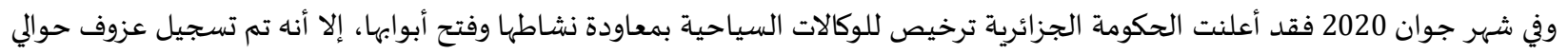

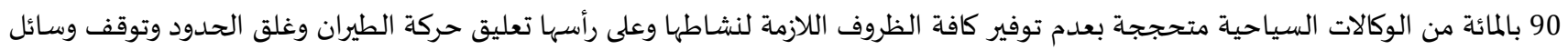

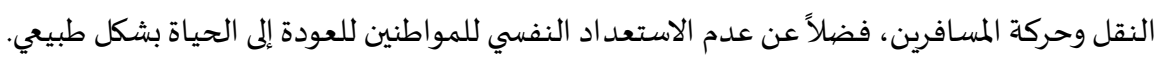

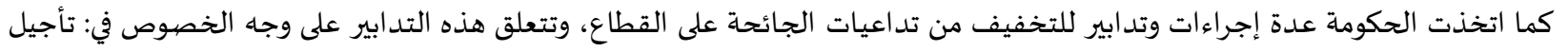

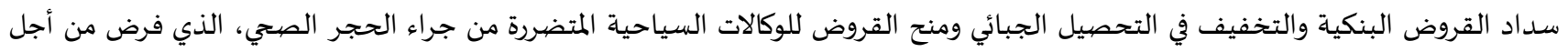

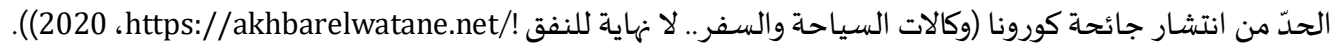

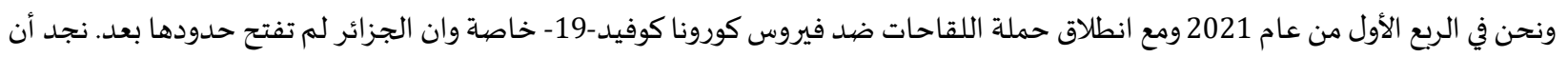

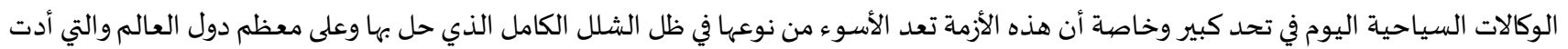
إلى خسائر بالمليارات، خاصة أن بوادر الانفراج غير واضحة على الأقل في المدى القصير. 
مسؤوليات الجهات الحكومية والوكالات السياحية لتخطي آثار الجائحة: يمكن الوقوف على مجموعة من الحلول أو المسؤوليات والتي تضمى .

مجموعة من الاقتراحات لتخطي الجائحة ونلخصها في نقطتين أساسيتين:

مسؤوليات الجهات الحكومية تجاه وكالات السياحة والأسفار: وتضم المقترحات الآتية:

1. الأكيد أن وضعية الإغلاق التام للمجال الجوي والبري والبحري لن يطول، وسيكون هناك فتح تدريجي ويختلف من بلد إلى آخر . لذا من المهات المهم جداً

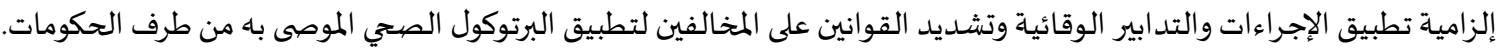

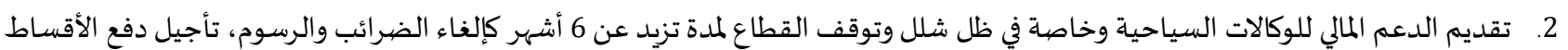

البنكية للوكلاء المقرضين، التعويضات للموظفين الذين تم تسريحهم ...الخ.

3. إقامة مركز لإدارة الأزمات والمخاطر على مستوى وزارة السياحة وكذلك انشاء فروع متخصصية في إدارة الأزمات على مستوى القطاعات السياحية

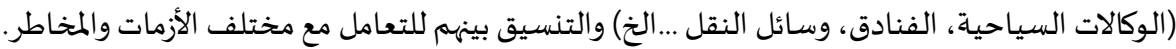

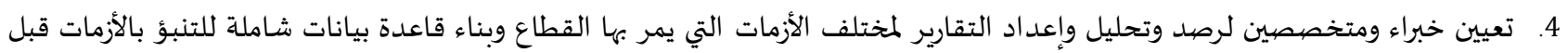

وقوعها.

5. تعزيز العلاقات بين وزارة السياحة والوكالات السياحية وباقي القطاعات السياحية الأخرى مع المؤسسات الإعلامية.

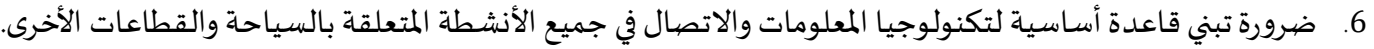

7. الاستفادة من تجارب الدول الأخرى في كيفية التغلب على الأزمات.

• مسؤوليات وكالات السياحة والأسفار: والتي تشمل المقترحات الآتية:

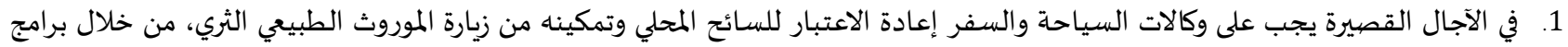
وعروض تغطي مختلف جهات الوطن وتراعي دخله، عكس ما كان عليه الحال من (قبل الجائحة) من اهتمام فقط ببرامج الحج والعمرة، مما جعل

البعض يسميها وكالات الحج والعمرة.

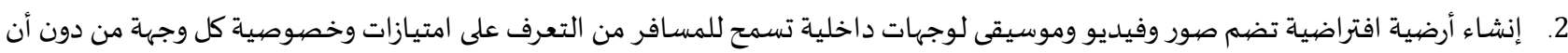

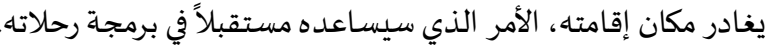

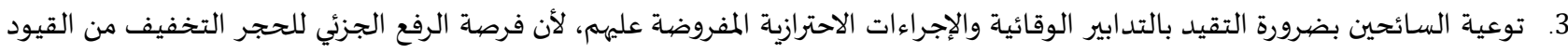

ليس معناه العودة إلى الممارسات المألوفة قبل الجائحة.

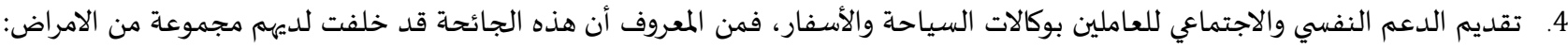

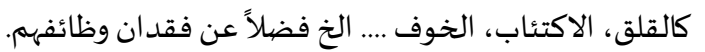

5.

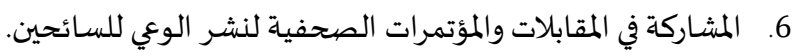

7.

8.

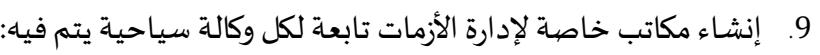

• عمل برامج تدريبية للعاملين في كيفية التعامل مع الأزمات وكيفية التعامل مع السائحين الذين سيترددون كثيراً في السفر بسبب آثار الجائحة.

• تعيين متحدث اعلامي مؤهل ليمثل الوكالة وقت الأزمة.



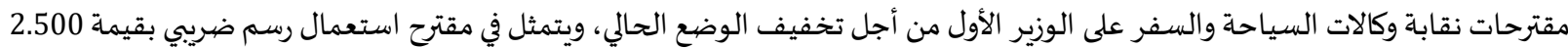

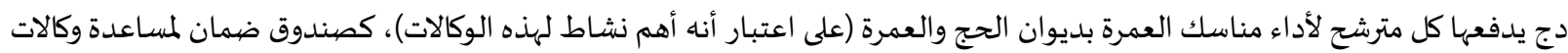

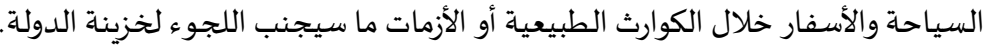




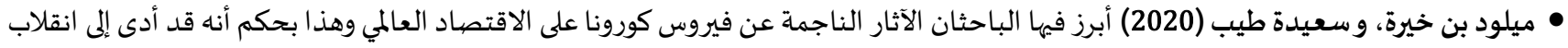

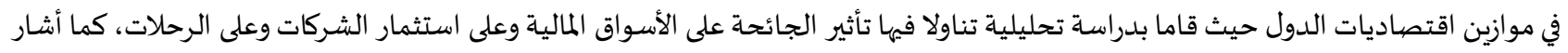

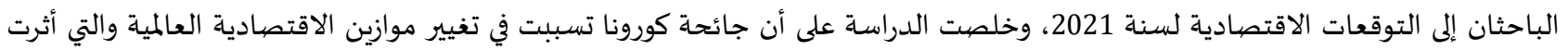

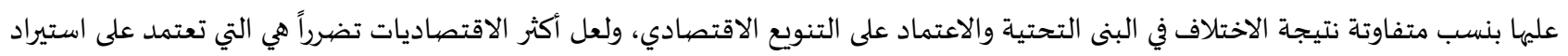
المواد الأولية وكذا البلدان التي تعتمد على السياحة.

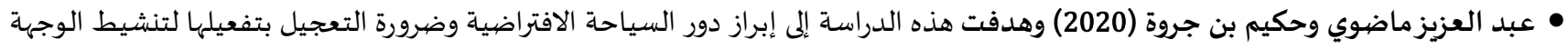

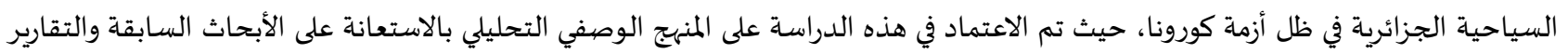

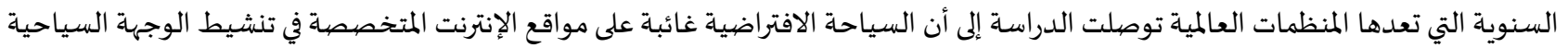

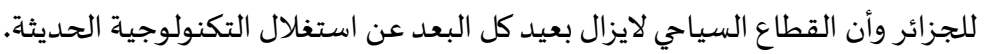

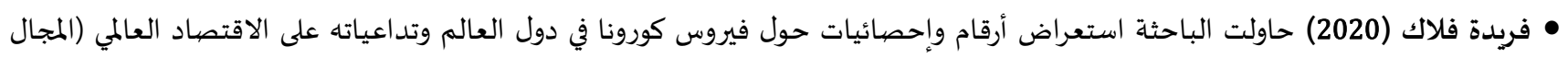

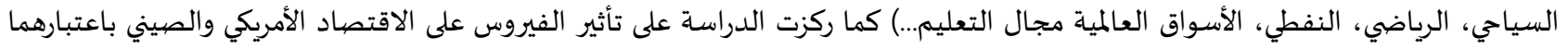

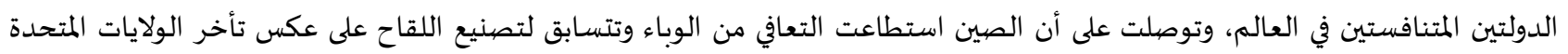
مقارنة بالصين، وهذا ما كشف عن هشاشة الأنظمة الصحية في كبريات الدول بما فهيا المتقدمة.

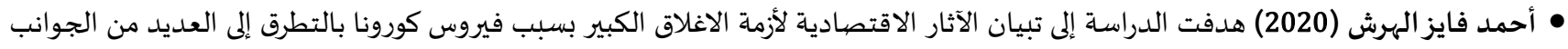

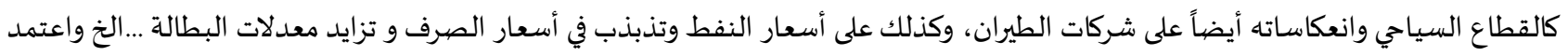

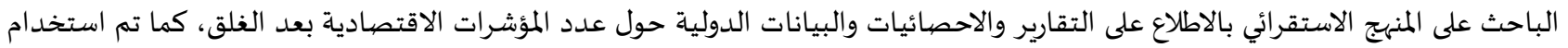

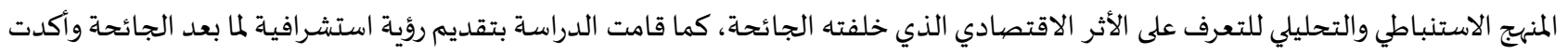

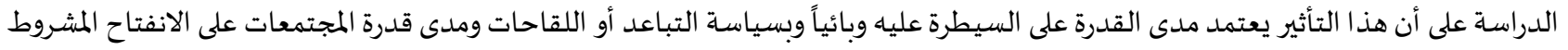

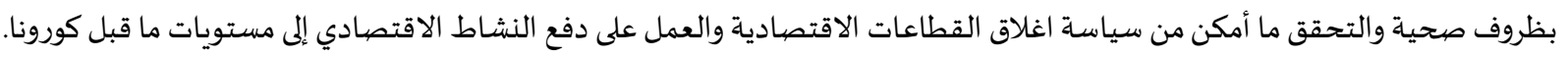

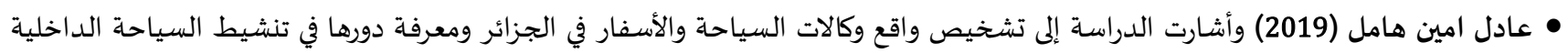

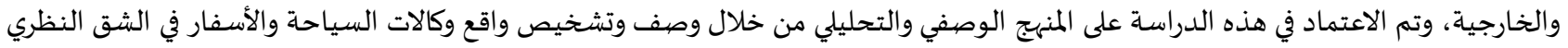

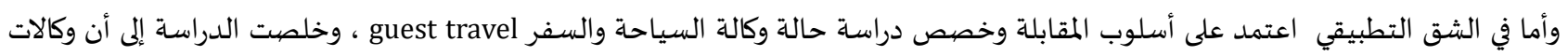

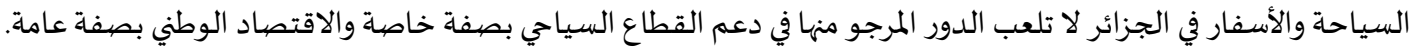
حيث أشارت الدراسة أنه مع ظهور فيروس كورونا اتخذت الحكومة الصينية إجراءات الحظر في منطقة يوهان

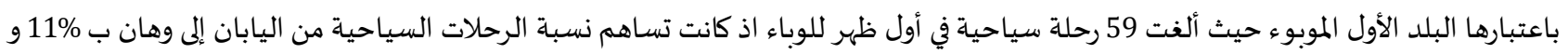

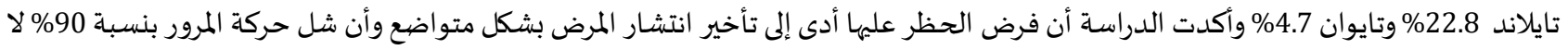
يكون لها جدوى ما لم تقترن بتدخلات الصحة العالمية والتغيرات السلوكية للمستهلكين.

مساهمة الدراسـة:

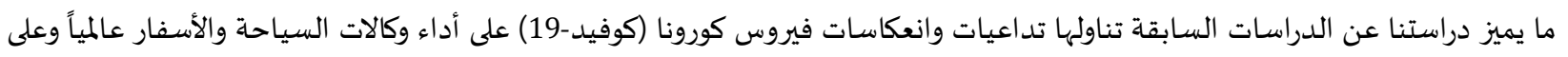

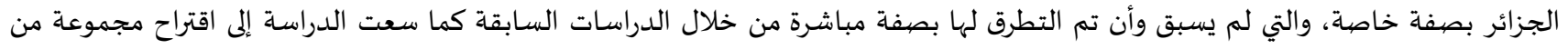
الحلول والتوصيات لتخطي آثار الجائحة. بهدف الإجابة على إشكالية الورقة البحثية والأسئلة الفرعية المطروحة، اعتمد الباحثين على المنهج الاستنباطي بأسلوبيه الوصفي والتحليلي.

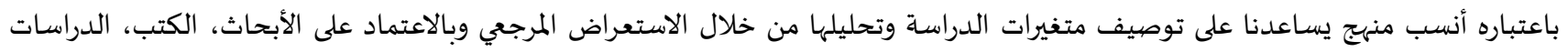

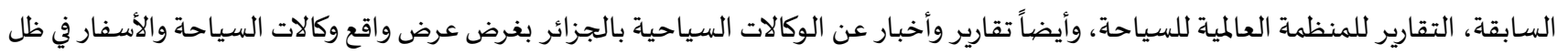

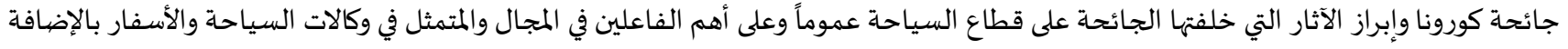


إلى تقديم مقترحات قد تساعد وكالات السياحة والسفر على تجاوز الأزمة على المدى القربب والبعيد لنتمكن في الأخير من عرض أهم النتائج وتقديم توصيات مناسبة.

2.3. فرضيات الدراسـة:

الفرضية الأولى: يمكن ان تساهم جائحة كورونا (كوفيد -19) في دفع وكالات السياحة والأسفار في الجزائر إلى حتمية مراجعة مزيج الخدمات التي تقدمها. الفرضية الثانية: يمكن أن تعود وكالات السياحة والأسفار في الجزائر بعد تجاوز جائحة كورونا (كوفيد -19) أقوى مما كانت عليه. 4. (النتائج والتوصيات: 1.4 فيما يلي أهم ما توصلت إليه الدراسـة من نتائج: جائحة كوفيد-19 أكبر من أن تنحصر في أزمة صحية، فهي كارثة إنسانية أدت إلى تغيرات وتحولات هاجمت قلب المجتمعات و اقتصادياتها، فكان لزاماً على الدول أن تزاوج ببن متناقضين هما استمرارية النشاط الاقتصادي وبقاء عجدلة الإنتاج في البلاد مع الحد من انتشار المرض. جائحة فيروس كورونا (كوفيد-19) أدت إلى توقف تام وكلي لأي نشاط سياحي، مما تسبب في إلغاء وكالات السياحة والسفر لكل البرامج السياحية

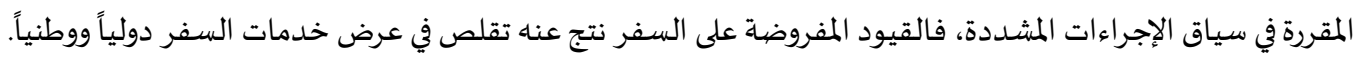
تسببت جائحة كورونا إلى إفلاس كثير من شركات الطيران، وصرحت منظمئمة الطيران المدني أن مجال الطيران ليس بمقدوره العودة إلى سابق عهده قبل الوباء إلا بحلول سنة 2024. إن إلغاء موسم الحج للأجانب وتجميد أداء مناسك العمرة يعتبر ضربة جد موجعة لوكالات السياحة والسفر الوطنية، على اعتبار أن الحج

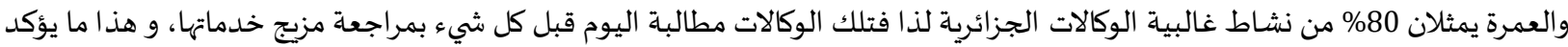
صحة الفرضياة الأولى. عدم إدراك القائمون على قطاع السياحة في الجزائر وبالخصوص وكالات السياحة والأسفار بأهمية السياحة الافتراضية، خاصة في ظل الظروف التي يعيشها العالم جراء فيروس كورونا. يمكن ان تساهم جائحة كورونا (كوفيد -19) في دفع وكالات السياحة والأسفار في الجزائر إلى لعب دور مهم جداً الإعطاء قطاع السياحة في الجزائر

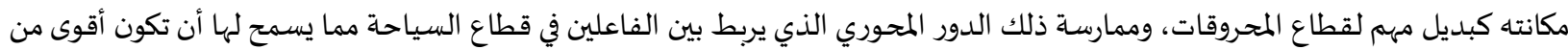
ذي قبل، وهذا ما يؤكد صححة الفرضية الثانية.

وفيما يلي جملة توصيات قد تسـاعد على التخفيف من الآثار الناتجاة عن الجائحة وتساهم في وضع أسس جديدة: وضعية الإغلاق التام للمجال الجوي والبري والبحري لن يطول، وسيكون هناك فتح تدريجي ويختلف من بلد إلى آخر. لذا من المهم جداً إلزامية تطبيق الإجراءات والتدابير الوقائية والاحترازية المفروضية. الحكومات مطالبة بتقديم الدعم لمختلف الفاعلين في القطاع السياحي دون استثناء. وعلى رأسهم وكالات السياحة والأسفار. ضرورة التفكير في تبني فكرة صندوق إعانات موجه إلى وكالات السياحة والسفر، على اعتبار أن السائح في اتصاله المباشر مع الوكالات يجعل هذه الأخيرة تتحمل أعباء الفاعلين الآخرين. وكالات السياحة والسفر الوطنية خصوصاً مطالبة أكثر من أي وقت مضى بإعادة الاعتبار إلى السياحة الداخلية كأحد أهم أنشطتها وبرامجها السياحية كبديل مهم جدا للممارسات التي كانت قبل جائحة كورونا وهذا ما يدعم فكرة الفرضية الأولى على ضرورة توسيع مزيج خدمات وهات وكالات السياحة والأسفار. وكالات السياحة والسفر الوطنية مطالبة بتوظيف التكنولوجيا في نشاطها، كأن تقترح على السـائح زيارات إلكترونية لعديد الوجهات (الوطنية أساساً والعالميية)، من باب التعريف ومن باب تهيئة الطلب السياحي إلى ما بعد الجائحة. الأكيد أنه سيكون هناك عودة تدريجية للنشاط السياحي ومن ثم لنشاط وكالات السياحة والسفر، على الأقل وطنياً في البداية وبعدها خارج الحدود حسب التطورات الصحية، وعليه من المهم جداً احترام التدابير الوقائية والصحية من خلال وضع بروتوكول صيحي صارم والتأكد والحرص على احترامه، حتى لا تكون هناك عودة إلى نقطة الصفر وتزايد منحنى الإصابات. 
يجب مراجعة كل ما له علاقة بوكالات السياحة والأسفار من قوانين تأسيسية وتنظيمية وآليات عملها، بهدف تمكينها من ممارسة دورها كقاطرة

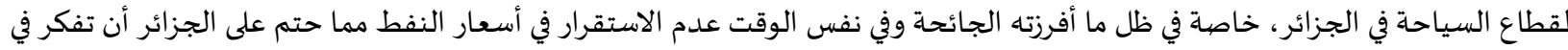
بديل حقيقي لقطاع المحروقات، ويعتبر قطاع السياحة من بين أهم القطاعات التي تعول عليها الجزائر الجديدة. من المهم جداً أن تنظر وكالات السياحة والأسفار إلى جائحة كورونا كفرصة مهمة جدا للارتقاء بقطاع السياحة إلى مكانته الأصلية كمصدر للثروة، خاصة إذا علمنا أن الإرث السياحي الذي تزخر به الجزائر يوحي لك وأنك في قارة وليس بلد بفعل ذلك الثراء الثراء والتنوع خاصة الطبيعي هذا

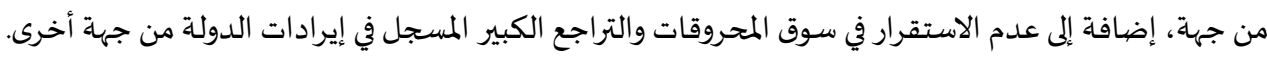

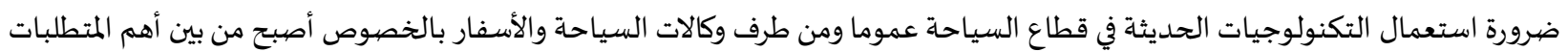
التي أفرزتها جائحة كورونا.

المقترحات للدراسـات المستقبلية: عنوان الورقة البحثية عبارة عن مساهمة علمية لتوصيف أحد القطاعات التي تأثرت بجائحة كورونا ألا و هو قطاع السياحة، وكان التركيز على

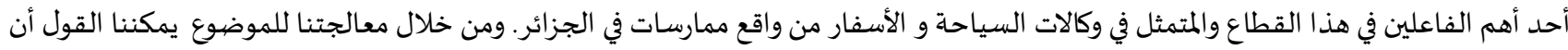

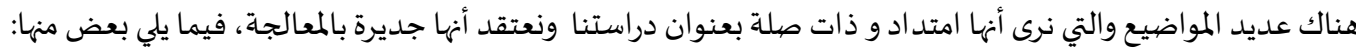
متطلبات ترقية قطاع السياحة في الجزائر. السياحة الإفتراضية فرصة أمام وكالات السياحة والأسفار في الجزائر للحفاظ على بقاتهاتها. آليات و سبل تنشيط السياحة الداخلية في الجزائر.

الخلاصية:

في ختام هذه الورقة البحثية يمكننا القول إن العالم مرت عليه أزمات عدة لكن ما حدث في 2020 مع جائحة فيروس كورونا (كوفيد-19)، سيبقى في التاريخ لسبب رئيسي وهو أن العالم بأسره دون استثناء تأثر؛ حكومات عانت وأنشطة توقفت (اقتصادية، اجتماعية، ثقافياة، رياضياة، دينية. إلخ)،

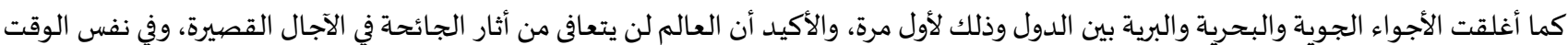
لن يبقى مكتوف الأيدي. وقد حاولنا من خلال هذه الورقة البحثية استعراض أحد القطاعات الاقتصادية التي تأثرت بشكل كبير جداً، ألا وهو القطاع السياحي بمختلف

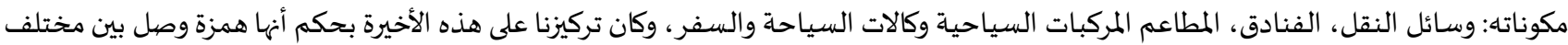
الفاعلين في القطاع السياحي من مقدمي الخدمات السابقة الذكر والسائح.

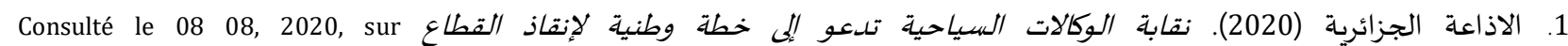
file:///C:/Users/HP/Desktop. 2. بليدي، ص . Consulté le 08 08, 2020, . Consulté le 08 08, 2020, sur 4. الجزيرة (2020). تحقيق للجزيرة نت بالأرقام.. هكذا أثر فيروس كورونا على السياحة والطيران بالمنطقة , Consulté le 08 11, 2020.

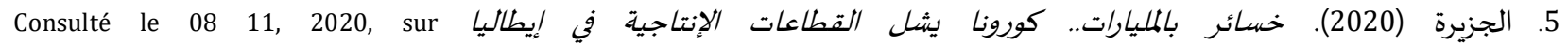
https://www.aljazeera.net/ebusiness/2020/3/8/.

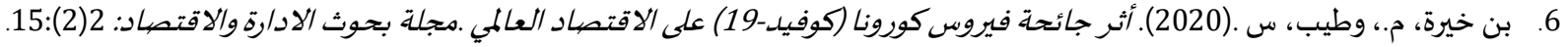

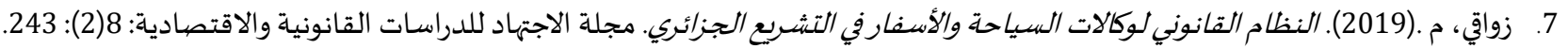

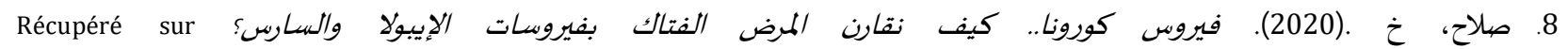

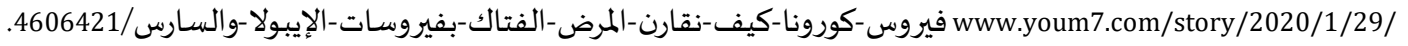
9. العمري، أ.، شيخ، ع، وعوادي، ع.(2019). مساهمة وكالات السياحة والأسفار كأحد المقومات الاساسية لتنشيط الطلب على المنتوج السياحي

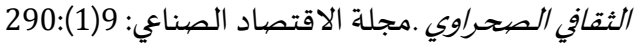
10. فلاك، ف .(2020). أرقام وإحصائيات حول أزمة كورونا الحديثة وتداعياتها على الاقتصاديات الكبرى في العالم "الولايات المتحدة الامريكية والصين ."مجلة التمكين الاجتماعي: 2 (2):53. 
. 2020, 03 12). Consulté le 07 06, 2020, sur فيروس كورونا: لماذا صنفته منظمة الصحة العالمية وباءً عالميا https://www.bbc.com/arabic/science-and-tech-51854975: $15: 05$

12. قرزيز، أ.، وبن زيان، أ. (2019). دور وكالات السياحة والسفرفي تنمية سياحة مستدامة دراسة ميدانية لعينة من وكالات السياحة والسفر بولاية باتنة .مجلة الاقتصياد الصناعي: 9 (2): 109.

13. ماضوي، ع.، وبن جروة، ح .(2020). نحو تفعيل السياحة الافتراضية لتنشيط الوجهات السياحية في ظل أزمة فيروس كورونا المستججل كوفيد19: مع الاشارة الى حالة الجزائر .مجلة بحوثل جروث الادارة والاقتصاد: 2 (2): 52.

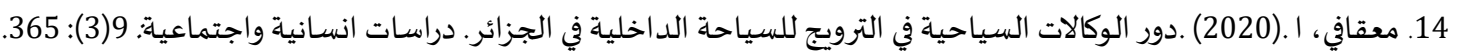

15. مهمل، ع .(2019). واقع وكالات السياحة والأسفار في الجزائر ودورها في التنشيط السياحي-دراسة حالة- مجلة التنمية وادارة الموارد البشرية

بحوث ودراسات: $6(2): 4$.

16. الهرش، أ.(2020). أزمة الاغلاق الكبيز: الآثار الاقتصادية لفيروس كورونا كوفيد-19 ـمجلة بحوث الادارة والاقتصاد: 2(2): 120.

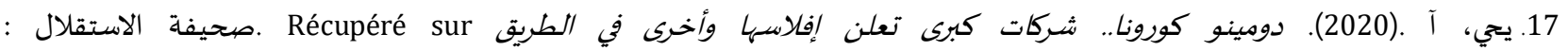
https://www.alestiklal.net/ar/view/4656/dep-news-1588352796

18.

ثانياً: المراجع الأجنبية:

1. Chinazzi, M., \& oth. (2020). The effect of tavel restrictions on th spread of the novel 2019coronavirus (COVID-19) outbreak. http://science.sciencemag.org/ Downloaded from, 395.

2. Guan, W. et al. (2020). Clinical Characteristics of Coronavirus disease 2019 in China. The New England Journal of Médicine, 1709.

3. IBISWorld. (2020). Global Hotels \& Resorts Industry - Market Research Report. Consulté le 08 10, 2020 , sur https://www.ibisworld.com/global/market-research-reports/global-hotels-resorts-industry/.

4. IBISWorld. (2020). Global Travel Agency Services Industry - Market Research Report. Consulté le 08 10, 2020 , sur https://www.ibisworld.com/global/market-research-reports/global-travel-agency-services-industry/.

5. Insider, B. (2020). كورونا أجبر شركات الطيران هذه على إعلان إفلاسها Récupéré sur CNBC عربية : https://www.cnbcarabia.com/news/view/67175/

6. Mayo Clinic Staff. (2020). مرض فيروس كورونا المستجد 2019 (كوفيد-19). Consulté le 06 07, 2020, sur www.mayoclinic.org/ar/diseasesconditions/coronavirus/symptoms-causes/syc-20479963 : 15 :00.

7. Suryawanshi, R., \& More, V. (2020). A Study of Effect of Corona Virus Covid-19 and Lock Down onHuman Psychology of Pune City Region. Studies in Indian Place Names(UGC Care Journal), 40, 965. 
International Journal of Hospitality and Tourism Studies (IJHTS)

Journal Homepage: https://www.refaad.com/views/IJHTS/home.aspx

www.refaad.com

ISSN 2709-0892 (Online) ISSN 2709-0884 (Print)

\title{
The implications of the Corona pandemic (Covid-19) on the performance of travel and tourism agencies
}

\author{
Smail Hassiba \\ Faculty of Faculty of Economics, Management and Commercial Sciences at Chlef University, Algeria \\ h.smail@univ-chlef.dz \\ Bennafla kaddour \\ Faculty Faculty of Economics, Management and Commercial Sciences at Chlef University, Algeria \\ k.bennafla@univ-chlef.dz
}

Received: 5/4/2021 Revised: 19/5/2021 Accepted: 22/6/2021 DOI: https://doi.org/10.31559/IJHTS2020.2.1.2

\begin{abstract}
This study aims to highlight the implications and effects of the Corona pandemic (Covid-19) on the performance of travel and tourism agencies globally and nationally; as well as the most-important actions and measures taken to reduce the spread of the pandemic. Besides, it sought to present the policies adopted by some countries in order to deal with the crisis in the field of tourism.

The two researchers relied on the deductive approach, with its descriptive and analytical methods, in order to collect information about the emerging corona virus, and its impact on the performance of travel and tourism agencies globally and nationally.

The results showed that the Corona pandemic has had a significant negative impact on the economies of all countries. It is noteworthy that tourism is among the most affected sectors, as many tourism agencies are threatened by bankruptcy, and many of them dismissed large numbers of employees. This also applies to various facilities related to tourism services (airlines, hotels, restaurants, etc...) considering the fact that the recovery period will be long due to the repeated borders closure and the recurrence of quarantine in some areas. This situation requires urgent government intervention to support travel and tourism agencies and tourism activities, in addition to the establishment of special crisis management offices for each tourist agency and supporting virtual tourism to revive the activity of agencies.
\end{abstract}

Keywords: Corona COVID-19 virus; travel agencies; pandemic consequences.

\section{References:}

1. Al'mry, A., Shykh, ', W'wady, '.(2019). Msahmh Wkalat Alsyahh Walasfar Kahd Almqwmat Alasasyh Ltnshyt Altlb 'la Almntwj Alsyahy Althqafy Alshrawy. Mjlt Alaqtsad Alsna'y: 9(1): 290.

2. Alada'h Aljza'ryh.(2020) Nqabh Alwkalat Alsyahyh Td'w Ela Khth Wtnyh Lenqad Alqta'. Consulté Le 08 08, 2020 , Sur File://C:/Users/Hp/Desktop.

3. Blydy, S. (2020). Wkalat Alasfar Aljza'ryh Tdf'e Fatwrh Ehmal Qta' Alsyahh. Consulté Le 08 08, 2020,

4. Dans L. A. (2020). Alsyny, Aldlyl Alshaml Lfyrws Kwrwna Almstjd (M'arf 'amh-Trq Alwqayh-Alr'ayh Alnfsyh-Alsha"at) Alqahrh (S3).

5. Flak, F. (2020). Arqam Wehsa'yat Hwl Azmh Kwrwna Alhdythh Wtda'yatha 'la Alaqtsadyat Alkbra Fy Al'alm "Alwlayat Almthdh Alamrykyh Walsyn". Mjlt Altmkyn Alajtma'y: 2 (2):53.

6. Fyrws Kwrwna: Lmada Snfth Mnzmt Alshh Al'ealmyh Wba'an 'almya. (2020, 03 12). Consulté Le 07 06, 2020 , Sur https://www.bbc.com/arabic/science-and-tech-51854975 : $15: 05$

7. Alhrsh, A.(2020). Azmh Alaghlaq Alkbyr: Alathar Alaqtsadyh Lfyrws Kwrwna Kwfyd-19. Mjlh Bhwth Aladarh Walaqtsad: 2(2): 120 .

8. Jbryl, H. (2020). Aljza'r.. 620 Mlywn Dwlar Khsa'r Shrkat Alnql Waltaqh Walsyahh. Consulté Le 08 08, 2020, Sur 
9. Aljzyrh.(2020) Thqyq Lljzyrh Nt Balarqam.. Hkda Athr Fyrws Kwrwna 'la Alsyahh Waltyran Balmntqh. Consulté Le 0811 , 2020,

10. Aljzyrh.(2020) Khsa'r Balmlyarat.. Kwrwna Yshl Alqta'at Alentajyh Fy Eytalya. Consulté Le 08 11, 2020 , Sur Https://Www.Aljazeera.Net/Ebusiness/2020/3/8/.

11. Bn Khyrh, M., Wtyb, S. (2020). Athr Ja'hh Fyrws Kwrwna (Kwfyd-19) 'la Alaqtsad Al'almy. Mjlt Bhwth Aladarh Walaqtsad: 2(2):15.

12. M'qafy, A. (2020). Dwr Alwkalat Alsyahyh Fy Altrwyj Llsyahh Aldakhlyh Fy Aljza'r. Drasat Ansanyh Wajtma'yh: 9 (3): 365.

13. Madwy, 'E., Wbn Jrwh, H. (2020). Nhw Tf'yl Alsyahh Alaftradyh Ltnshyt Alwjhat Alsyahyh Fy Zl Azmh Fyrws Kwrwna Almstjd Kwfyd-19: M' Alasharh Ala Halh Aljza'r. Mjlt Bhwth Aladarh Walaqtsad: 2 (2): 52.

14. Mhml, '.(2019). Waq' Wkalat Alsyahh Walasfar Fy Aljza'r Wdwrha Fy Altnshyt Alsyahy-Drash Halh- Mjlt Altnmyh Wadart Almward Albshryh Bhwth Wdrasat: 6(2): 4.

15. Qrzyz, A., Wbn Zyan, A. (2019). Dwr Wkalat Alsyahh Walsfr Fy Tnmyt Syahh Mstdamh Drash Mydanyh L'ynh Mn Wkalat Alsyahh Walsfr Bwlayh Batnh. Mjlt Alaqtsad Alsna'y: 9 (2): 109.

16. Slah, Kh.(2020). Fyrws Kwrwna.. Kyf Nqarn Almrd Alftak Bfyrwsat Aleybwla Walsars? Récupéré Sur www.youm7.com/story/2020/1/29/ fyrws-kwrwna-kyf-nqarn-almrd-alftak-bfyrwsat-aleybwla-walsars/4606421.

17. Yhy, A.(2020). Dwmynw Kwrwna.. Shrkat Kbra T'ln Eflasha Wakhra Fy Altryq. Récupéré Sur Shyfh Alastqlal: https://www.alestiklal.net/ar/view/4656/dep-news-1588352796.

18. Zwaqy, M.(2019). Alnzam Alqanwny Lwkalat Alsyahh Walasfar Fy Altshry' Aljza'ry. Mjlh Alajthad Lldrasat Alqanwnyh Walaqtsadyh: 8(2): 243. 